\title{
Enfermedad por citomegalovirus en niños chilenos infectados por el virus de la inmunodeficiencia humana-1
}

\author{
Anamaría Peña D., Carmen Larrañaga L., Vivian Luchsinger F., Julia Villarroel B., Ana Chávez P., \\ Elba Wu H. y Comité Nacional de SIDA Pediátrico, Sociedad Chilena de Pediatría
}

\section{Cytomegalovirus disease in HIV-1 infected Chilean children}

Cytomegalovirus (CMV) is a frequent opportunistic infection in human inmunodeficiency virus type 1 (HIV-1) infected children associated with significant morbidity and mortality. The aim of this study was to determine the frequency and impact of CMV disease in a prospectively followed cohort of HIV-1 infected Chilean children. CMV disease was diagnosed in 28 out of 222 HIV infected children (12.6\%); $92 \%$ of them were classified in category $\mathrm{C}$ and $61 \%$ in category 3 (CDC, 1994). Lung disease was the most common manifestation (25 children). Samples were obtained from the respiratory tract, blood, urine and tissue biopsies. Shell vial for CMV early antigen detection was the most commonly used diagnostic technique (20/ 28). All patients were treated with iv.ganciclovir and two children died during the CMV episode. The mean survival time for the remaining children is currently 42 months. Conclusion: CMV disease was frequent and caused mortality in HIV-1 infected Chilean children. Early diagnosis and treatment are key for clinical success.

Key words: cytomegalovirus, human immunodeficiency virus type 1, children.

Palabras claves: citomegalovirus, virus de inmunodeficiencia humana tipo 1, niños.

\section{Introducción}

$\mathrm{C}$ itomegalovirus (CMV) es uno de los agentes oportunistas que con mayor frecuencia afecta a los pacientes infectados con el virus de la inmunodeficiencia humana (VIH). El riesgo de infección por CMV en estos niños es más alto que en la población infantil sana, ya sea adquirido en forma congénita, teniendo en cuenta la alta frecuencia de coinfección durante el embarazo en mujeres portadoras del VIH, o por la infección postnatal que ocurre, principalmente, en los primeros años de vida ${ }^{1-5}$.

La infección por CMV produce alta morbilidad en niños infectados por VIH y en ellos, su letalidad alcanza al 30\%. La enfermedad por CMV representa el 8 a $10 \%$ de las enfermedades marcadoras de síndrome de inmunodeficiencia adquirida (SIDA) ${ }^{6-8}$. Es frecuente que sea la primera manifestación de SIDA, constituyendo motivo para sospechar la pre-existencia de infección por VIH.

Debido a la ausencia de publicaciones sobre esta enfermedad en la población infantil infectada con VIH en Chile, se estudiaron los casos de enfermedad causada por este virus registrados en la cohorte nacional de VIH pediátrico, con el fin de describir su frecuencia, presentación clínica, la respuesta al tratamiento y profilaxis indicados, y el tiempo de sobrevida.

\section{Pacientes y Método}

Se realizó un estudio descriptivo y retrospectivo en un total de 222 niños chilenos infectados con VIH, hijos de madre seropositivas para VIH, que en su evolución presentaron enfermedad por CMV, entre enero de 1989 y julio de 2005. En todos ellos, se concluyó que el mecanismo de transmisión de la infección por VIH fue vertical. Para ello, se consideró la evidencia de infección materna por este virus y la ausencia de otras fuentes de infección.

Se definió enfermedad por $C M V$ a aquella entidad clínica con manifestaciones sugerentes y evidencias de replicación viral en muestras correspondientes al órgano blanco, o que cumplía con dos de las siguientes condiciones: estudio histológico característico, respuesta clínica al tratamiento antiviral específico y ausencia de otros agentes patógenos (Tabla 1) ${ }^{9}$. Se consideró probable enfermedad por CMV si, en ausencia de replicación viral evidente, el cuadro clínico se asoció sólo a una de las condiciones señaladas (Tabla 1). Se excluyeron de este estudio los casos con infección activa por CMV (aislamiento de virus) en ausencia de síntomas clínicos.

Se revisaron las fichas clínicas de los pacientes y se consignó la edad del diagnóstico de infección por VIH y por CMV, la etapa clínica de la infección VIH al

\author{
Pontificia Universidad Católica \\ de Chile, Santiago, Chile \\ Hospital Dr. Sótero del Río (APD) \\ Universidad de Chile \\ Facultad de Medicina, \\ Programa de Virología (CLL, VLF) \\ Hospital San Juan de Dios, \\ Santiago (EWH) \\ Hospital Dr. Félix Bulnes Cerda, \\ Santiago, Chile (JVB) \\ Hospital Dr. Exequiel González \\ Cortés, Santiago, Chile (ACHP) \\ Recibido: 16-01-07 \\ Aceptado: 24-09-07 \\ Correspondencia a: \\ Anamaría Peña Donati \\ anapena@med.puc.cl
}




\section{Tabla 1. Criterios de enfermedad por CMV}

\section{Enfermedad por CMV}

Clínica sugerente y replicación viral activa en órgano (s) blanco

Clínica sugerente, histología probable y respuesta clínica a tratamiento

Clínica sugerente, respuesta clínica a tratamiento y ausencia de otros patógenos

\section{Probable enfermedad por CMV}

Clínica sugerente e histología probable

Clínica sugerente y respuesta clínica a tratamiento

Clínica sugerente y ausencia de otros patógenos
* Adaptado de ref 9 ca y aislamiento viral. En casos de sospecha de esofagitis se realizó endoscopia y biopsia esofágica. Las muestras fueron estudiadas mediante cortes histológicos y estudio microbiológico para CMV, virus herpes simplex y hongos. A todo paciente con infección por CMV confirmada se le practicó fondoscopia, de acuerdo con el protocolo de seguimiento de infecciones oportunistas. Finalmente, en los casos en que reaparecieron los síntomas, se repitió el estudio pertinente para descartar una recaída.

\section{Resultados}

En 28 de 222 (12,6\%) niños infectados con VIH, se momento del diagnóstico de enfermedad por CMV, el recuento de linfocitos TCD4 y la cuantificación de la carga viral de VIH. También se registraron las manifestaciones clínicas del episodio de CMV, los métodos de diagnóstico utilizados, el tratamiento y la profilaxis recibida, la evolución posterior al manejo terapéutico y la aparición de eventos de toxicidad atribuibles al uso de ganciclovir.

De acuerdo con el protocolo nacional de seguimiento de niños infectados con VIH del Comité Nacional de SIDA Pediátrico, en los pacientes con sospecha de infección por algún patógeno oportunista de origen pulmonar se realizó lavado bronco-alveolar para cultivo bacteriano, búsqueda de antígenos de virus respiratorios (VRS, influenza A y B, parainfluenza 1, 2, 3 y ADV), baciloscopia, cultivo de Koch, tinción para hongos, detección de antígeno de CMV (técnica de shell vial) y tinción argéntica de Gomori Grocott o RPC para Pneumocystis jiroveci. Cuando no se dispuso de lavado bronco-alveolar, el estudio etiológico se realizó a partir de otras muestras respiratorias, con mayor frecuencia, aspirado nasofaríngeo u oro-traqueal. En pacientes con diarrea crónica o refractaria se tomaron muestras para coprocultivo, parasitológico seriado de deposiciones, tinción para Criptosporidium en deposiciones, biopsia intestinal para microscopia electróni-

\begin{tabular}{l}
$\begin{array}{l}\text { Tabla 2. Frecuencia de la enfermedad por CMV } \\
\text { en niños infectados por VIH. Chile, } \\
\text { Enero 1988- Julio 2005 }\end{array}$ \\
$\begin{array}{l}\text { Casos } \\
\text { Niños infectados con VIH * }\end{array}$ \\
$\begin{array}{l}\text { Niños con enfermedad por CMV } \\
\text { * }\end{array}$ \\
\hline $\begin{array}{l}\text { *nforme semestral Instituto de Salud Pública de Chile. Julio } \\
2005\end{array}$
\end{tabular}
sospechó una enfermedad por CMV durante su evolución (Tabla 2). No se observaron diferencias de sexo entre los 222 pacientes en seguimiento, como tampoco entre los 28 casos con sospecha de enfermedad por CMV.

La mediana de edad al momento de plantearse el diagnóstico de enfermedad por CMV fue 7,5 meses. La distribución porcentual por grupo de edad se observa en la Tabla 3.

La enfermedad por CMV se confirmó en 25 de estos pacientes. En cinco casos se diagnosticó enfermedad diseminada debido al compromiso de dos o más órganos; en 17 neumopatía, y en los otros tres pacientes retinitis, esofagitis y colitis, respectivamente (se estableció como enfermedad probable ya que, pese a tener síntomas compatibles y haber respondido al tratamiento con ganciclovir, la enfermedad por CMV no se confirmó, porque el virus se aisló en muestras no representativas del órgano blanco en dos niños $\mathrm{y}$, en otro, se detectó en concomitancia con otros agentes) (Tabla 4).

Tabla 3. Distribución de los niños con infección por VIH y enfermedad por CMV, según edad. Chile, Enero 1988- Julio 2005

\begin{tabular}{lrr}
\hline Edad (meses) & $\mathbf{n}$ & $\%$ \\
\hline $1-6$ & 13 & 46,5 \\
$7-12$ & 2 & 7,1 \\
$13-24$ & 5 & 17,9 \\
$25-36$ & 2 & 7,1 \\
$37-48$ & 2 & 7,1 \\
49 o más & 4 & 14,3 \\
\hline Total & 28 & 100,0 \\
& & \\
\hline *Promedio: 22,9 meses; Mediana: 7,5 meses; Moda: 4 \\
meses; Rango: 2 m - 9 a 8 m
\end{tabular}




\begin{tabular}{|c|c|c|c|c|c|c|}
\hline $\begin{array}{l}\mathbf{n} \\
\text { aciente }\end{array}$ & Diagnóstico clínico & $\begin{array}{l}\text { Diagnóstico de } \\
\text { laboratorio }\end{array}$ & $\begin{array}{l}\text { Detección de } \\
\text { otro agente }\end{array}$ & Tratamiento & Evolución & $\begin{array}{l}\text { Conclusión } \\
\text { diagnóstica }\end{array}$ \\
\hline 1 & $\begin{array}{l}\text { Neumopatía, IRA, hepatitis, } \\
\text { anemia leucopenia, trombo- } \\
\text { citopenia, atrofia cerebral }\end{array}$ & $\begin{array}{l}\text { RPC cualitativa en LBA } \\
\text { Antigenemia } \\
\text { (27 núcleos positivos) }\end{array}$ & $\mathrm{NO}$ & Ganciclovir, VM & $\begin{array}{l}\text { Resolución de } \\
\text { enfermedad }\end{array}$ & $\begin{array}{l}\text { Enfermedad } \\
\text { diseminada por CMV }\end{array}$ \\
\hline 2 & $\begin{array}{l}\text { Neumopatía, anemia, } \\
\text { trombocitopenia, hepatitis, } \\
\text { calcificaciones cerebrales }\end{array}$ & $\begin{array}{l}\text { Antigenemia } \\
\text { RPC en tiempo real de sangre }\end{array}$ & NO & $\begin{array}{l}\text { Ganciclovir } \\
\text { Gamaglobulina }\end{array}$ & $\begin{array}{l}\text { Curación } \\
\text { Reactivación }\end{array}$ & $\begin{array}{l}\text { Enfermedad } \\
\text { diseminada por CMV }\end{array}$ \\
\hline 3 & $\begin{array}{l}\text { Neumopatía, IRA, hepatitis } \\
\text { granulomatosa, retinitis, } \\
\text { atrofia cerebral }\end{array}$ & $\begin{array}{l}\text { AV de AT y orina } \\
\text { Estudio inmunohistoquímica } \\
\text { en biopsia hepática }\end{array}$ & NO & $\begin{array}{l}\text { Ganciclovir } \\
\text { Gamaglobulina, VM }\end{array}$ & Resolución & $\begin{array}{l}\text { Enfermedad } \\
\text { diseminada por CMV }\end{array}$ \\
\hline 4 & $\begin{array}{l}\text { Neumopatía, IRA, hepatitis, } \\
\text { anemia, leucopenia, trombo- } \\
\text { citopenia, diarrea refractaria }\end{array}$ & $\begin{array}{l}\text { AVR de AT e histología en } \\
\text { tejido pulmonar }\end{array}$ & NO & $\begin{array}{l}\text { Ganciclovir, VM } \\
\text { Gamaglobulina }\end{array}$ & Resolución & $\begin{array}{l}\text { Enfermedad } \\
\text { diseminada por CMV }\end{array}$ \\
\hline 5 & $\begin{array}{l}\text { Neumopatía, IRA, hepatitis, } \\
\text { diarrea refractaria, diplejia } \\
\text { espástica }\end{array}$ & AV de saliva & NO & $\begin{array}{l}\text { Ganciclovir, VM } \\
\text { Gamaglobulina }\end{array}$ & Resolución & $\begin{array}{l}\text { Enfermedad } \\
\text { diseminada por CMV }\end{array}$ \\
\hline 6 & Neumopatía & AVR en LBA & NO & $\begin{array}{l}\text { Ganciclovir } \\
\text { Gamaglobulina }\end{array}$ & Resolución & Neumopatía por CMV \\
\hline 7 & Neumopatía & AVR de LBA & Candida sp & $\begin{array}{l}\text { Ganciclovir } \\
\text { Gamaglobulina }\end{array}$ & Resolución & Neumopatía por CMV \\
\hline 8 & Neumopatía, IRA, emaciación & AVR de LBA & NO & $\begin{array}{l}\text { Ganciclovir, VM } \\
\text { Gamaglobulina }\end{array}$ & Resolución & Neumopatía por CMV \\
\hline 9 & Neumopatía, IRA, & AVR de LBA & NO & $\begin{array}{l}\text { Ganciclovir } \\
\text { Gamaglobulina, VM }\end{array}$ & Resolución & Neumopatía por CMV \\
\hline 10 & Neumopatía & AVR de LBA & NO & $\begin{array}{l}\text { Ganciclovir } \\
\text { Gamaglobulina }\end{array}$ & Resolución & Neumopatía por CMV \\
\hline 11 & $\begin{array}{l}\text { Neumopatía } \\
\text { Anemia, aumento transaminasas }\end{array}$ & AVR de LBA & NO & $\begin{array}{l}\text { Ganciclovir } \\
\text { Gamaglobulina }\end{array}$ & Resolución & Neumopatía por CMV \\
\hline 12 & $\begin{array}{l}\text { Neumopatía, IRA, anemia, } \\
\text { leucopenia }\end{array}$ & AVR de LBA & NO & $\begin{array}{l}\text { Ganciclovir } \\
\text { Gamaglobulina, VM }\end{array}$ & $\begin{array}{l}\text { Resolución } \\
\text { Recaída clínica }\end{array}$ & Neumopatía por CMV \\
\hline 13 & Neumopatía, anemia & AV de LBA, ANF, orina & NO & $\begin{array}{l}\text { Ganciclovir } \\
\text { Gamaglobulina }\end{array}$ & Resolución & Neumopatía por CMV \\
\hline 14 & Neumopatía & AV de LBA & NO & $\begin{array}{l}\text { Ganciclovir, } \\
\text { Foscarnet } \\
\text { Gamaglobulina }\end{array}$ & Resolución & Neumopatía por CMV \\
\hline 15 & $\begin{array}{l}\text { Neumopatía, elevación } \\
\text { transaminasas }\end{array}$ & AVR de LBA AV de orina & NO & $\begin{array}{l}\text { Ganciclovir } \\
\text { Gammaglobulina }\end{array}$ & Resolución & Neumopatía por CMV \\
\hline 16 & $\begin{array}{l}\text { Neumopatíaesofagitis, anemia, } \\
\text { hipotonía }\end{array}$ & AVR de AT & NO & $\begin{array}{l}\text { Ganciclovir } \\
\text { Gamaglobulina }\end{array}$ & Resolución & Neumopatía por CMV \\
\hline 17 & Neumopatía, neumotórax & AVR de AT & NO & Ganciclovir, VM & Resolución & Neumopatía por CMV \\
\hline 18 & Neumopatía, anemia & AVR de AT & NO & $\begin{array}{l}\text { Ganciclovir } \\
\text { Gamaglobulina }\end{array}$ & $\begin{array}{l}\text { Curación } \\
\text { Reactivación }\end{array}$ & Neumopatía por CMV \\
\hline 19 & $\begin{array}{l}\text { Neumopatía, IRA, anemia, } \\
\text { trombocitopenia, leucopenia, } \\
\text { aumento transaminasas }\end{array}$ & AVR de AT & NO & $\begin{array}{l}\text { Ganciclovir, VM } \\
\text { Gamaglobulina, }\end{array}$ & Fallece & $\begin{array}{l}\text { Neumopatía por } \\
\text { CMV }\end{array}$ \\
\hline 20 & $\begin{array}{l}\text { Neumopatía, IRA, diarrea } \\
\text { refractaria }\end{array}$ & AVR de AT & NO & $\begin{array}{l}\text { Ganciclovir,VM } \\
\text { Gamaglobulina, }\end{array}$ & Resolución & Neumopatía por CMV \\
\hline 21 & $\begin{array}{l}\text { Neumopatía, IRA, colestasia } \\
\text { hepática, retinitis }\end{array}$ & AVR de AT & NO & $\begin{array}{l}\text { Ganciclovir,VM } \\
\text { Gamaglobulin, }\end{array}$ & Resolución & Neumopatía por CMV \\
\hline 22 & Neumopatía, IRA, emaciación & AVR de AT & ADV en AT & $\begin{array}{l}\text { Ganciclovir,VM } \\
\text { Gamaglobulina }\end{array}$ & Fallece & $\begin{array}{l}\text { Neumopatía por CMV } \\
\text { y ADV }\end{array}$ \\
\hline 23 & Esofagitis & $\begin{array}{l}\text { Estudio histológico en } \\
\text { biopsia esofágica }\end{array}$ & NO & $\begin{array}{l}\text { Ganciclovir } \\
\text { Gamaglobulina }\end{array}$ & Resolución & Esofagitis por CMV \\
\hline 24 & Diarrea crónica & Estudio histológico en tejido & NO & Ganciclovir & Resolución & Colitis por CMV \\
\hline 25 & Retinitis & $\begin{array}{l}\text { Fondo de ojo compatible } \\
\text { AVR de orina }\end{array}$ & NO & $\begin{array}{l}\text { Ganciclovir } \\
\text { Gamaglobulina }\end{array}$ & Resolución & Retinitis por CMV \\
\hline 26 & $\begin{array}{l}\text { Neumopatía, hepatitis, anemia, } \\
\text { leucopenia, trombocitopenia, } \\
\text { diarrea refractaria }\end{array}$ & AVR y AV de ANF y AT & $\begin{array}{l}\text { Mycobacterium } \\
\text { tuberculosis en } \\
\text { AT y contenido } \\
\text { gástrico, y } \\
\text { S. pneumoniae } \\
\text { y Candida sp } \\
\text { en sangre }\end{array}$ & $\begin{array}{l}\text { Ganciclovir } \\
\text { Anfotericina B } \\
\text { Ceftriaxona } \\
\text { Tratamiento } \\
\text { Gamaglobulina }\end{array}$ & Resolución & $\begin{array}{l}\text { Probable enfermedad } \\
\text { por CMV }\end{array}$ \\
\hline 27 & Neumopatía, hepatitis & AVR de ANF & NO & $\begin{array}{l}\text { Ganciclovir } \\
\text { Gamaglobulina }\end{array}$ & Resolución & $\begin{array}{l}\text { Probable neumopatía } \\
\text { por CMV }\end{array}$ \\
\hline 28 & $\begin{array}{l}\text { Neumopatía, IRA, anemia, } \\
\text { trombocitopenia, diarrea } \\
\text { refractaria }\end{array}$ & AVR de ANF & Candida sp & $\begin{array}{l}\text { Ganciclovir } \\
\text { Gamaglobulina } \\
\text { Fluconazol, VM }\end{array}$ & Resolución & $\begin{array}{l}\text { Probable neumopatía } \\
\text { por CMV }\end{array}$ \\
\hline
\end{tabular}


El diagnóstico clínico más frecuente fue la neumopatía con presentación atípica (25/28 casos, $89,3 \%)$. Doce niños evolucionaron con insuficiencia respiratoria aguda y en dos se realizó el diagnóstico de síndrome de distress respiratorio del adulto. Todos ellos requirieron ventilación mecánica, con una duración promedio de 14 días en 11 niños (rango: 4-27 días); en un caso, el soporte ventilatorio se prolongó durante 10 meses (Tabla 4).

En cinco casos, una diarrea de curso prolongado y refractario a los tratamientos habituales, fue la principal manifestación del compromiso digestivo. En un caso, la evolución crónica de la diarrea motivó la sospecha de infección por $\mathrm{CMV}$, diagnóstico que se confirmó mediante el estudio histológico de la biopsia intestinal. En uno de los dos niños con esofagitis, ésta fue la manifestación inicial de enfermedad; en él, el diagnóstico específico de CMV se hizo a partir de la biopsia. Uno de los ocho casos con hepatitis evolucionó con colestasia intrahepática y otros tres presentaron elevación significativa de las transaminasas hepáticas (Tabla 4).

La anemia, en distintos grados, se presentó en 11 niños; en cinco se observó leucopenia y en seis trombocitopenia (Tabla 4).
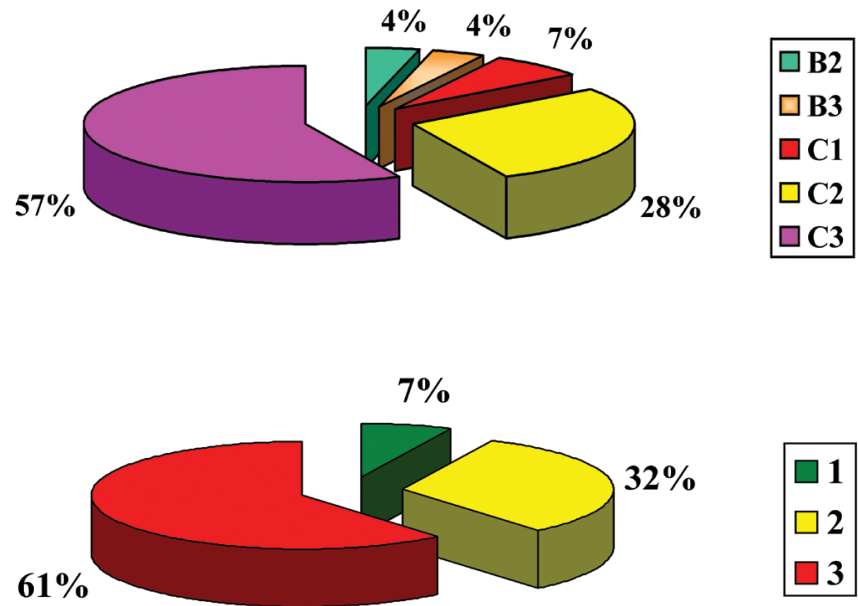

Recuento células TCD4 Mediana $303 \times$ mm$^{3}$ Rango $20-1986 \times$ mm$^{3}$

Figura 1. Distribución de la Clasificación CDC 1994 para las etapas clínico-inmunológicas de la infección por virus de la inmunodeficiencia humana en niños menores de 13 años con enfermedad por CMV. Chile, Enero 1988-2005.
La evaluación neurológica demostró compromiso del SNC en cinco niños: atrofia cerebral en dos pacientes, diplejía espástica, síndrome hipotónico y calcificaciones cerebrales en un caso, respectivamente. En dos de tres niños con retinitis, hubo desprendimiento de retina (Tabla 4).

El intervalo de tiempo entre el diagnóstico de infección por VIH y la enfermedad por CMV fue de 0 a 105 meses. En 15 pacientes (56\%), la enfermedad por CMV correspondió a la primera manifestación de la infección por VIH. Al momento del diagnóstico de la enfermedad por CMV, 92\% de los niños fueron clasificados en la etapa C (categoría clínica) de la clasificación del CDC, año $1994^{8}$, para niños infectados por VIH. Ningún niño se clasificó en las etapas $\mathrm{N}$ o A (Figura 1).

En 26 niños se realizó el recuento de LT CD4 al momento del diagnóstico de la enfermedad por CMV; la mediana del recuento fue 303 células $/ \mathrm{mm}^{3}$ (rango: 20-1.986 células $/ \mathrm{mm}^{3}$ ), con un porcentaje (en relación a linfocitos totales) de $14 \%$ (rango: $1-43 \%$ ). Siete por ciento de los niños se clasificó en la etapa inmunológica $1,32 \%$ en etapa 2 y $61 \%$ en etapa 3 , de acuerdo con la clasificación CDC-1994 (Figura 1). Sólo 40\% de los lactantes bajo un año de edad tenía inmunodepresión grave al momento del diagnóstico de enfermedad por CMV (Tabla 5).

En 19 casos se determinó la carga viral de VIH al diagnosticar la enfermedad por CMV. La mediana fue 180.000 copias ARN/ml (rango: no detectable a 17.000.000 copias ARN/ml).

Once pacientes habían iniciado terapia anti-retroviral (TARV) antes de presentar la enfermedad por CMV. Tres de ellos recibían biterapia, siete triterapia y un paciente recibía cuatro anti-retrovirales. Este último, al igual que dos niños con biterapia y tres con triterapia, no habían respondido a la TARV indicada.

El CMV fue detectado en muestras respiratorias en la mayoría de los niños: lavado bronco-alveolar en 11 casos, aspirado traqueal en diez y aspirado nasofaríngeo en cuatro niños. En cuatro pacientes el estudio

Tabla 5. Porcentaje de TCD4 en los menores de 13 meses con infección VIH y enfermedad por CMV. Chile, Enero 1988-Julio 2005

\begin{tabular}{|lrr|}
\hline \% TCD4 & n & \multicolumn{1}{c|}{$\%$} \\
\hline$<15$ & 6 & 40 \\
$5-24$ & 6 & 40 \\
$>25$ & 3 & 20 \\
\hline Total & 15 & 100,0 \\
\hline *Mediana: 14\%; Rango : $1-43 \%$ & & \\
\hline
\end{tabular}


se realizó en orina, en dos en sangre y en uno en saliva. El método de diagnóstico más utilizado fue la detección de antígeno precoz mediante shell vial -20 pacientes-, seguido del aislamiento viral (6 casos), detección de ADN viral por RPC y antigenemia en dos, respectivamente. La histología fue el método diagnóstico en cuatro niños (Tabla 4).

Todos los pacientes fueron tratados con ganciclovir ev en dosis de $10 \mathrm{mg} / \mathrm{kg} /$ día. El tratamiento se prolongó por 21 días en fase de inducción, excepto en el niño con colitis, en el que se extendió a 30 días. En un caso se asoció foscarnet en dosis de $180 \mathrm{mg} / \mathrm{kg} / \mathrm{dí}$. Dieciocho niños recibieron ganciclovir ev tres veces por semana, entre 21 y 69 dosis, como fase de mantención.

Sólo en un niño se confirmó toxicidad por ganciclovir, la que se manifestó como agravamiento de la anemia leve que estaba presente al inicio de la enfermedad por CMV, situación que revirtió tras la finalización del tratamiento. En otro caso se sospechó toxicidad hepática; sin embargo, ésta fue descartada por la biopsia que demostró una hepatitis granulomatosa compatible con daño por CMV. A 22 niños se les administró 400 $\mathrm{mg} / \mathrm{kg}$ de inmunoglobulina ev cada 21 a 30 días.

Sobrevivieron 26 niños y sólo tres presentaron una evolución tórpida. Dos niños fallecieron (letalidad de $7,1 \%$ ). El episodio de enfermedad por CMV se resolvió en 2,4 meses en promedio (rango: 1-8 meses; moda: 1 mes). En los pacientes en los que el tratamiento fue exitoso, la sobrevida, al cierre del estudio, alcanzaba un promedio de 42 meses, con un rango de 3 a 130 meses. Hubo recaída de la enfermedad en tres casos, cumplidos 1, 2 y 18 meses del episodio inicial, respectivamente. Dos pacientes con retinitis evolucionaron a la ceguera unilateral. Actualmente, permanecen vivos 22 niños. Cuatro pacientes fallecieron en etapa de SIDA terminal, posteriormente, por causas no asociadas al CMV: dos de ellos por diarrea intratable y emaciación, uno por meningitis y neumopatía y el último por accidente vascular encefálico y colangitis.

En 17 de los 26 sobrevivientes se administró profilaxis secundaria. En siete de ellos se usó ganciclovir ev tres veces por semana, en tres por vía oral, y en uno se utilizó valganciclovir. Seis de estos 17 niños recibieron aciclovir oral transitoriamente, durante el período en que no se disponía en el país de ganciclovir para uso oral. La duración promedio de la profilaxis secundaria fue de 5,5 meses (rango 1 a 18 meses).

El CMV se detectó en concomitancia con otros agentes oportunistas en cuatro pacientes. En dos casos de neumopatía grave se encontró Candida sp en muestras respiratorias; su participación como agente causal es difícil de establecer, considerándose al CMV responsable de esta patología. En un paciente con neumopatía, insuficiencia respiratoria y emaciación, la asociación de CMV y ADV resultó fatal. En otro caso, pese a la detección de Mycobacterium tuberculosis, Streptococcus pneumoniae y Candida sp, se consideró a CMV como el principal responsable de las manifestaciones generalizadas que presentaba el paciente (neumopatía grave con insuficiencia respiratoria, anemia, leucopenia, trombocitopenia y diarrea refractaria).

\section{Discusión}

Citomegalovirus es uno de los principales agentes oportunistas en los pacientes infectados con VIH. En los niños, el riesgo de infectarse por CMV es mayor y la infección se adquiere más precozmente que en quienes no tienen VIH. Así, sólo $15 \%$ de los recién nacidos no infectados con VIH se infecta con CMV antes de los seis meses de edad; en comparación, $40 \%$ de los lactantes infectados por VIH adquieren el CMV hasta esta edad ${ }^{6}$. En nuestros pacientes, la mediana de edad del diagnóstico de CMV fue 7,5 meses; en más de la mitad de los casos éste se hizo antes del año de edad y en 13 antes de los 7 meses de vida. Si bien no es posible determinar si la edad en que se detectaron los síntomas corresponde al momento de la primoinfección, podemos afirmar que $82 \%$ de los niños estaba infectado por CMV antes de los cuatro años de edad. Este hallazgo es concordante con lo señalado en la literatura científica: el riesgo de la infección se mantiene alto en los primeros cuatro años de vida ${ }^{6}$.

La enfermedad por CMV es indicadora de $\operatorname{SIDA}^{6,8}$ y este virus acelera la progresión de la infección por VIH y contribuye al deterioro inmunológico del paciente $\mathrm{e}^{6,7,11}$. Así, los niños que adquieren el VIH en forma vertical y además se infectan con CMV antes de nacer o en los primeros meses de vida, progresan más rápidamente a SIDA. Se ha descrito que a los 18 meses de edad, 70\% ya presentará el SIDA, en comparación con $30 \%$ de los niños infectados únicamente por $\mathrm{VIH}^{6}$. El $92 \%$ de nuestros pacientes se encontraba en etapa de SIDA al momento del diagnóstico de enfermedad por CMV y $61 \%$ en etapa inmunológica 3 . Estos resultados corroboran que la enfermedad por CMV se presenta en pacientes con bajos recuentos de $\mathrm{LT}$ CD $4^{10}$, es decir, cuando la inmunodeficiencia es grave. No obstante, en el grupo de lactantes bajo 12 meses de edad $40 \%$ tenía inmunodepresión moderada y en $20 \%$ el recuento de LTCD4 era normal. Por esto, es necesario investigar la infección por CMV en forma precoz en este grupo etario, independiente del grado de compromiso inmune.

La enfermedad por CMV en adultos, generalmente es monosintomática, comprometiendo, principalmente, la retina o el tracto digestivo ${ }^{11,12,14}$. Por el contrario, 
en niños, si bien el CMV puede comprometer sólo un órgano -generalmente pulmón, intestino o la retina-, lo más frecuente es la enfermedad generalizada, con neumopatía de rápida progresión hacia la insuficiencia respiratoria, compromiso hematológico, hepático, del tracto digestivo, neurológico y de retina. De acuerdo con esto, 64\% de los niños estudiados tenía compromiso de más de dos órganos y la forma de presentación principal fue la pulmonar $(88,5 \%)$. Las manifestaciones clínicas incluyen síntomas respiratorios, úlceras orales y esofágicas que pueden progresar hasta la perforación, disfagia, diarrea prolongada o crónica con frecuencia sanguinolenta-, ictericia, hepatomegalia, esplenomegalia y hematuria. Los hallazgos de laboratorio más frecuentes son anemia, leucopenia, trombocitopenia, elevación de la deshidrogenasa láctica, bilirrubina y transaminasas hepáticas, hematuria y cilindruria. Por tal motivo, en todo niño co-infectado con VIH y CMV debe realizarse un estudio funcional de todos los parénquimas potencialmente comprometidos, incluyendo hemograma, recuento de plaquetas, función hepática y renal, orina completa, deshidrogenasa láctica, radiografía de tórax, fondoscopia, evaluación neurológica, estudio de LCR y TAC si se sospecha una meningo-encefalitis, endoscopia digestiva baja en casos de diarrea inveterada, o alta si se sospecha de una esofagitis.

La retinitis es una de las complicaciones más graves y se presenta como una lesión inicialmente periférica y unilateral, con edema, hemorragia y, finalmente, necrosis de la retina. El inicio tardío del tratamiento no impide la progresión rápida al ojo contralateral, produciendo secuelas muchas veces invalidantes ${ }^{14,15}$. En todos los niños con CMV en esta serie se realizó fondoscopia, diagnosticándose retinitis en tres; dos de ellos evolucionaron a la ceguera unilateral. En niños pequeños con infección por VIH, en quienes se detecta CMV en cualquier muestra, debe practicarse la fondoscopia en forma rutinaria. En niños mayores y adultos, la pérdida de la visión central o periférica, escotomas o visión de partículas flotantes, permiten sospechar su diagnóstico oportunamente. Se recomienda, incluso, realizar fondoscopia cada 4 a 6 meses en lactantes y prescolares co-infectados con $\mathrm{CMV}$, especialmente, cuando su inmunodepresión es grave; en escolares debe buscarse la sintomatología correspondiente y según cada caso, solicitar la evaluación oftalmológica ${ }^{19}$.

El compromiso neurológico también es frecuente y puede manifestarse en forma aguda, como meningoencefalitis, habiéndose descrito casos con mielitis y poliradiculopatía $^{10,16}$. Cuando la infección por CMV ocurre tempranamente in útero, se presenta con microcefalia, calcificaciones cerebrales, sordera y retardo mental, entre otras manifestaciones ${ }^{17}$. Sólo en un niño se encontró microcefalia y calcificaciones cerebrales, sugiriendo que la infección por CMV fue adquirida durante la gestación. En los otros cuatro pacientes que presentaron compromiso neurológico, no fue posible afirmar si sus secuelas obedecían a la infección por VIH, por CMV o por ambos agentes.

La enfermedad por CMV puede evolucionar con sordera, tanto en la forma congénita como en la infección postnatal. Se considera la principal causa de sordera en niños pequeños $\operatorname{sanos}^{18}$. En nuestro grupo no se ha evaluado el compromiso auditivo, el que deberá ser incluido en un protocolo de seguimiento a futuro.

Para el diagnóstico de CMV, la detección de IgG en el lactante bajo un año de edad no es útil debido al traspaso de anticuerpos maternos. La pesquisa de IgM puede arrojar falsos positivos y negativos. El aislamiento de CMV en orina de recién nacidos hijos de madres infectadas con VIH, en las primeras dos semanas de vida, confirma la infección congénita; su ausencia, por el contrario, descarta esta infección intrauterina. Para la detección oportuna de las infecciones citomegálicas, los expertos recomiendan efectuar serología y aislamiento viral en muestras de orina, en forma anual, en niños infectados por VIH. Esta pesquisa es particularmente útil en niños seronegativos para CMV o con cultivos virales negativos ${ }^{19}$. El aislamiento viral rápido-shell vial, en el cual se combina el cultivo celular con la detección de antígenos tempranos por inmunofluorescencia, permite identificar en forma rápida y específica la presencia del virus en replicación, en la muestra. Esta técnica ha sido aplicada, de preferencia, en orina y saliva; en nuestra experiencia, la antigenemia (detección del antígeno p65), tiene bajo rendimiento en niños pequeños. La RPC cualitativa no permite discriminar entre infección y enfermedad por CMV en algunos tipos de muestras y aún no se establecen valores de corte indicadores de enfermedad para la RPC cuantitativa; ambas tienen un costo eleva$\mathrm{do}^{20}$. El diagnóstico se hizo de preferencia en muestras respiratorias utilizando el método de shell vial, especialmente, desde lavado bronco-alveolar o aspirado traqueal. El Comité Nacional de SIDA Pediátrico propone que en los pacientes con neumopatía atípica se estudien patógenos habituales y oportunistas en el lavado bronco-alveolar, lo que explica la precocidad del diagnóstico y la efectividad del tratamiento alcanzada en esta serie.

La terapia recomendada para la enfermedad por CMV, incluida la retinitis, es ganciclovir ev y, como alternativa, puede emplearse foscarnet. En casos graves puede asociarse ambos antivirales. Trabajos recientes han demostrado la eficacia de dos dosis diarias de ganciclovir ev durante dos semanas, seguido de ganciclovir 
oral como terapia de mantención ${ }^{21}$. En niños sobre tres años de edad, afectados por retinitis, se pueden asociar inyecciones de ganciclovir o foscarnet intravítreo o como implante intraocular, con ganciclovir oral ${ }^{19,22}$. Todos nuestros pacientes fueron tratados con ganciclovir ev y sólo uno requirió también foscarnet. Si bien estos antivirales pueden causar efectos adversos graves ${ }^{19}$, en ninguno de ellos debió suspenderse la terapia por esta causa.

En niños con serología positiva para CMV e inmunodepresión grave, se recomienda el uso de profilaxis primaria, es decir, prevenir el primer evento de enfermedad por esta causa. Se sugiere utilizar ganciclovir oral, aunque no existe consenso entre los autores, dado su alto costo y los posibles efectos adver$\operatorname{sos}^{23}$. Hasta ahora, el énfasis está enfocado a la pesquisa precoz de la replicación viral en eventos sospechosos.

En todos los niños infectados con VIH que desarrollan enfermedad por CMV se ha recomendado profilaxis secundaria de por vida, para prevenir la recurrencia $^{19,23}$. Ésta puede hacerse con $5 \mathrm{mg} / \mathrm{kg} /$ día de ganciclovir ev, 3 a 5 veces por semana; tratamiento limitado por la necesidad de instalar un catéter venoso central. La medicación oral es ideal, pero la formulación pediátrica de valganciclovir no está disponible en nuestro país y sólo existe una publicación sobre su uso en niños ${ }^{24}$. En 25 de los 26 sobrevivientes se realizó profilaxis secundaria, cuya principal dificultad fue mantener la vía venosa. Tres casos debieron tratarse nuevamente debido a la reactivación del cuadro clínico. Ningún niño se ha mantenido con profilaxis de por vida, probablemente porque en la mayoría se inició TARV o se cambió el esquema anti-retroviral, lográndose una buena adherencia. Si bien no existen recomendaciones específicas para la suspensión de la profilaxis secundaria, se ha comprobado que el uso de HAART (terapia anti-retroviral altamente activa) disminuye la incidencia y recurrencia de los eventos oportunistas. En un estudio multicéntrico ${ }^{25}$, se concluyó que, en niños, es posible suspender la profilaxis secundaria para patógenos oportunistas después de seis meses de HAART con buena adherencia y con recuentos de LT CD4 superiores a 20\%, a partir de los seis años y sobre $25 \%$ bajo esta edad.

Otras publicaciones demuestran que la enfermedad por CMV, generalmente, es grave y de alta mortalidad si ocurre antes de los 18 meses de edad ${ }^{6}$. En nuestro grupo de pacientes la resolución del evento se logró con tratamiento convencional y más del $90 \%$ no presentó nuevos episodios. La explicación de estos resultados y de la letalidad inferior a la descrita en la literatura médica probablemente se fundamente en la precocidad del diagnóstico e inicio del tratamiento.

CMV es un agente frecuente de morbilidad en niños con VIH. El diagnóstico y tratamiento oportuno permiten una buena evolución de esta enfermedad, por lo que es necesario mantener la búsqueda de CMV en estos pacientes. La pesquisa debe incluir a los hijos de madre portadora de VIH durante las primeras semanas post parto, en una muestra de orina o saliva. Asimismo, se debe insistir en las medidas preventivas para evitar la adquisición de CMV en los niños infectados con VIH, consistentes en: educar a sus padres o cuidadores sobre los mecanismos de transmisión del CMV; mantener una adecuada higiene; evaluar los riesgos que implica la asistencia a sala cuna y jardín infantil $\mathrm{y}$, en caso de transfusión sanguínea, utilizar filtros adecuados.

Agradecimientos. A Sras. María Isabel Campos, secretaria y Mónica Peña, tecnóloga médico del Programa de Virología de la Facultad de Medicina de la Universidad de Chile por su colaboración en la recepción y procesamiento de las muestras clínicas.

\section{Resumen}

Citomegalovirus (CMV) es una infección oportunista frecuente en niños infectados con el virus de la inmunodeficiencia humana tipo 1 (VIH 1) y produce altas tasas de morbilidad y mortalidad. El objetivo de este estudio fue determinar la frecuencia y trascendencia de la enfermedad por CMV en la cohorte de niños chilenos infectados con VIH-1. Se encontró enfermedad por CMV en 28 de 222 niños infectados con VIH-1 (12,6\%); $92 \%$ fue clasificado en etapa C y $61 \%$ en categoría 3 (CDC 1994). La enfermedad pulmonar fue la manifestación más común (25). Las muestras clínicas se obtuvieron de tracto respiratorio, sangre, orina y biopsia. Para la detección de CMV se utilizó, preferentemente, el cultivo acelerado (shell vial), (20/28). Todos fueron tratados con ganciclovir ev. El tiempo promedio de sobrevida fue 42 meses hasta el momento de esta evaluación. Conclusión: La enfermedad por CMV causó morbilidad y mortalidad en los niños chilenos infectados por VIH-1. El diagnóstico y tratamiento precoces son la base para un resultado exitoso. 


\section{Referencias}

1.- Mussi-Pinhata M, Yamamoto A, Figueiredo L, Cervi M, Duarte G. Congenital and perinatal cytomegalovirus infection in infants born to mothers infected with human immunodeficiency virus. J Pediatr 1998; 132: 285-90.

2.- Marodi L. Cytomegalovirus in HIV-infected newborns. Pediatr Res 2000; 47: 173.

3.- Prover C G, Enright A M. Congenital cytomegalovirus (CMV) infections: hats off to Alabama. J Pediatr 2003; 143: 4-6.

4.- Likinukul S, Bhattarakosol P, Poovorawan Y. Seroprevalence of cytomegalovirus infection in children born to HIV-1 women. Asian Pac J Allergy Immunol 2003; 21: 127-30.

5.- Chakraborty R, Rees G, Bourboulia D, Cross A, Dixon J, D'Agostino A et al. Viral coinfections among African children infected with human immunodeficiency virus type 1 . Clin Infect Dis 2003; 36: 922-4.

6.- Kovacs A, Schluchter M, Easley K, Demmler G, Shearer W, Russa P, et al. Cytomegalovirus infection and HIV-1 disease progression in infants born to HIV-1 infected women. The pediatric pulmonary and cardiovascular complications of vertically transmitted HIV infection Study Group. N Engl J Med 1999; 341: 77-84.

7.- Doyle M, Atkins JT, Rivera-Matos I. Congenital cytomegalovirus infection in infants infected with human immunodeficiency virus. Pediatr Infect Dis J 1996; 15: 1102-6.

8.- Centers for Disease Control and Prevention. 1994 revised classification system for Human Immunodeficiency Virus infection in children less 13 years age. MMWR Morbid Mortal Wkly Rep 1994; 43: 1-17.
9.- Gentile G, Picardi A, Capobianchi A Spagnoli A, Cudillo C, et al. A prospective study comparing quantitative cytomegalovirus (CMV) polymerase chain reaction in plasma and pp64 antigenemia assay in monitoring patients after allogeneic stem cell transplantation. BMC Infectious Diseases 2006, 6: 167.

10.- Chandwani S, Kaul A, Bebenroth D, Kim M, Di John D, Fidelia A, et al. Cytomegalovirus infection in human immunodeficiency virus type 1-infected children. Pediatr Infect Dis J 1996; 15: 310-4.

11.- Skolnik P R, Kosloff B R, Hirsch M S. Bidirectional interactions between human immunodeficiency virus type 1 and cytomegalovirus. J Infect Dis 1988; 157: 508-14.

12.- Jabs D A, Van Natta M L, Kempen J H, Reed Pavan P, Lim J I, Murphy R L, et al. Characteristics of patients with cytomegalovirus retinitis in the era of highly active antiretroviral therapy. Am J Ophthalmol 2002; 133: 48-61.

13.- Dieterich DT, Rahmin M. Cytomegalovirus colitis in AIDS: presentation in 44 patients and a review of the literature. J Acquir Immun Defic Syndr 1991; 4 (Suppl 1): 29-35.

14.- Van Even G, Mauck K, Gumbel H, Richter R. Prevalence ant treatment of cytomegalovirus-retinitis in HIV-infected children. Int Conf AIDS 1996 Jul 7-12; 11: 135 (abstract $\mathrm{N}^{\mathrm{o}}$ We.C.3447).

15.- Verdaguer J I, Verdaguer J, Valdivia H, Varela C, López M. Estudio clínico en retinis por citomegalovirus. Arch Chil Oftalmol 2000; 57: 57-68.

16. - Marriage S, Booy R, Lyall H, Evans J, Owens C, Watkins P, et al. Cytomegalovirus myelitis in a child infected with human immunodeficiency virus type 1 . Pediatr Infect Dis J 1996; 15: 549-51.
17.- Pass R, Fowler K, Boppana S, Britt W, Stagno S. Congenital cytomegalovirus infection following first trimester maternal infection: symptoms at birth and outcome. J Clin Virol 2006; 35: 216-20.

18.- Ross S, Fowler K, Ashrith G, Stagno S, Britt W, Pass R, et al. Hearing loss in children with congenital cytomegalovirus infection born to mothers with preexisting immunity. J Pediatr 2006; 148: 332-6.

19. - Centers for Disease Control and Prevention. Treating opportunistic infections among HIV-exposed and infected children. MMWR Morbid Mortal Wkly Rep 2004/53 (RR14); 34-7.

20.- Storch GA. Diagnostic virology. Clin Infect Dis 2000; 31: 739-51.

21.- Sayito A, Viani R, Schrier R, Spector S. Treatment of infants coinfected with HIV-1 and cytomegalovirus with combination antiretrovirals and ganciclovir. J Allergy Clin Immunol 2004; 114: 983-5.

22.- Van Even G, Mauck K, Gumbel H, Richter R, Ohrloff C. Prevalence and treatment of cytomegalovirus-retinitis in HIV-infected children. Int Conf AIDS 1996 Jul 7-12; 11: 135 (abstract $n^{\circ}$ We. C.3447).

23.- Centers for Disease Control and Prevention. Guidelines for preventing opportunistic infections among HIV-infected persons. MMWR Morbid Mortal Wkly Rep June 14, 2002/51(RR08): 1-46.

24.- Burri M. Oral valganciclovir in children: single dose pharmacokinetics in a six-yearold girl. Pediatr Infect Dis J 2004; 23: 263-6.

25.- Nachman S, Gona P, Dankner W, Weinberg A, Yogev R, Gershon A, et al. The rate of serious bacterial infections among HIV-infected children with immune reconstitution who have discontinued opportunistic infection prophylaxis. Pediatrics 2005; 115: 488-94. 